\title{
Influence of T6 Solution Heat Treatment and Intermetallic Particles Addition on the Hardness and Tensile Properties of Al-Si (A413) Alloys
}

\author{
Sridhar T, H R Manohara, Basava T
}

\begin{abstract}
This paper reflects on the influence of T6 solution heat treatment on A413 and its alloys. Heat treatment carried out at a particular temperature, time and methods are to bring changes in mechanical properties of the material. T6 solution heat treatment performed by heating the specimens at $525{ }^{\circ} \mathrm{C}$ for a period of 8 hours and then quenched in water at $65^{\circ} \mathrm{C}$ is considered followed by artificial aging is done at $155{ }^{\circ} \mathrm{C}$ for 8 hours in hot air oven. Vickers micro-hardness tester used is to determine the hardness of specimen and UTM-2T was used to determine the tensile properties of the specimen. From the above investigation it is observed that the hardness of the A413 has significantly improved with T6 heat treatment process and also found that the tensile properties of the A413 improved when heat treated of the specimen.
\end{abstract}

Keywords: T6 solution heat treatment, A413, Artificial aging, Hardness, Tensile Properties, ASTM.

\section{INTRODUCTION}

Aluminium based alloys have unique properties as high strength, non-corrosive, resistance to wear and light weight, used widely in industries because of their light weight and castability strength. The common alloy elements used with Aluminium are copper, magnesium, manganese, silicon, tin and zinc. A413 is a eutectic alloy contains $10-13 \%$ silicon used in aerospace and automobile industries because of its good machinability and castability. Al-Si alloys are used for pistons, cylinders, blocks and heads of IC engines in automobile and aeronautical industries [1-3].

Heat Treatment is an operation or combination of operations involving heating at a specific rate, soaking at a temperature for a period of time and cooling at some specified rate. The aim is to obtain a desired hardness along with tensile strength and elongation to achieve certain predetermined. To tailor the properties of any alloy or metal (Al-Si) component for design purpose, the tailored materials need to undergo different form conditioning and finishing, however the typical heat treatment are conducted to ensure the alloys meet the desirable result [2-4].

Eutectic Al-Si alloys [10-13\% silicon] find wide applications in marine, chemical, food and domestic, electrical automotive, aeronautical sectors and engine parts. It is well known that metals and alloys solidify with coarse columnar grain structure under normal casting conditions unless the mode of solidification is carefully controlled. It is

\footnotetext{
Revised Manuscript Received on 14 August, 2019.

Sridhar T, H R Manohara, SDM Institute of Technology, Ujire - 574 240, Karnataka, India(Email: sridharkhl@gmail.com)

H R Manohara, PG Student, Department of Mechanical Engineering, Malla Reddy Engineering College, Secunderabad India

Basava T,SDM Institute of Technology, Ujire - 574 240, Karnataka,
}

possible to develop fine equiaxed grain in the cast structure either by increasing the number of nucleation sites or by grain multiplication [5]. The interest in grain refinement technique stems from the fact that the grain size of the particles are greatly influence on the mechanical properties of any metal or alloy component. Grain size is one of the important parameter in determining the mechanical properties of $\mathrm{Al}-\mathrm{Si}$ alloys and according to Hall-Petch equation [5], high strength can be attained in fine-grained Al-Si alloys. M. A. Moustafa et.al [4] investigated that all alloying elements $(\mathrm{Mg}, \mathrm{Cu}, \mathrm{Sr}, \mathrm{Ni}$, and $\mathrm{B})$ performs a better role in improving the hardness and strengths of A413.1 automotive alloy, more significantly improved particularly after heat treatment.

In this paper, we did an effort to study the effect of T6 solution heat treatment on the Mechanical Properties of eutectic Al-Si (A413) and its alloys.

\section{II.EXPERIMENTAL}

The specimens needed for experiments are prepared by using induction furnace with casting process. The optimised compositions of intermetallic particles are as in the table 1 .

Table 1.The optimized additions of \% of intermetallic particles with A413 alloy.

\begin{tabular}{|c|c|c|c|}
\hline $\begin{array}{l}\text { Sl. } \\
\text { No } \\
\text { - }\end{array}$ & $\begin{array}{l}\text { Na } \\
\text { me } \\
\text { of } \\
\text { allo } \\
y\end{array}$ & 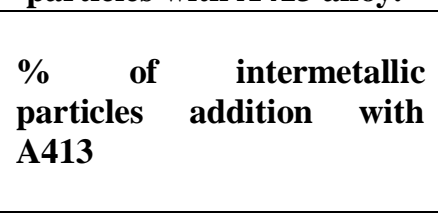 & $\begin{array}{l}\text { holding } \\
\text { time of } \\
\text { Melt }\end{array}$ \\
\hline 1 & $1 \mathrm{~A} 1$ & As CastA413 & $0 * \min$ \\
\hline 2 & 2A1 & $\begin{array}{ll}\text { As CastA413+0.27\% } & \text { Al- } \\
5 \% \mathrm{Al}_{3} \text { Ti master alloys } & \end{array}$ & $5 \mathrm{~min}$ \\
\hline 3 & $3 \mathrm{~A} 1$ & $\begin{array}{lrl}\text { As } & \text { CastA413+0.6\% } & \text { Al- } \\
3 \% \mathrm{AlB}_{2} \text { master alloys } & \\
\end{array}$ & $5 \mathrm{~min}$ \\
\hline 4 & 4A1 & $\begin{array}{lll}\text { As } & \text { CastA } 413+0.55 \% & \text { Al- } \\
3 \% \mathrm{TiB}_{2} \text { master alloys } & \\
\end{array}$ & $5 \mathrm{~min}$ \\
\hline 5 & $5 \mathrm{~A} 1$ & $\begin{array}{lll}\text { As } & \text { CastA413 +0.3\% } & \text { Al- } \\
10 \% \mathrm{Al}_{4} \mathrm{Sr} \text { master alloys } & \end{array}$ & $5 \mathrm{~min}$ \\
\hline 6 & $6 \mathrm{~A} 1$ & $\begin{array}{l}\text { As CastA } 413+0.55 \% \text { Al- } \\
3 \% \mathrm{TiB}_{2} \\
+0.3 \% \mathrm{Al}-10 \% \mathrm{Al}_{4} \mathrm{Sr} \text { master } \\
\text { alloys }\end{array}$ & $5 \mathrm{~min}$ \\
\hline
\end{tabular}

" 0 " means No holding time for Melt because it is ascastA413. 
The specimens were developed by using induction furnace and graphite crucible. The as cast (A413) is placed in graphite crucible and melted at $720^{\circ} \mathrm{C}$ temperature. The molten metal is then degassed with using solid hexachlorothane $(\mathrm{C} 2 \mathrm{Cl} 6)$ followed by adding the weighted intermetallic particles as mentioned in table 1 into crucible [6]. Then molten melt is stirred for $30 \mathrm{~s}$ for better reinforcement the same is poured into pre-heated graphite crucibles of size $100 \mathrm{~mm}$ length and $12.5 \mathrm{~mm}$ diameter for tensile specimens and in to $100 \mathrm{~mm}$ length and $25 \mathrm{~mm}$ diameter pre heated graphite crucibles for Hardness specimens. The cast bars were machined as per ASTM standard to conduct tensile test and Hardness test. The machined specimens were further heat treated as per ASTM T6 Solution heat treatment in muffle furnace around $525^{\circ} \mathrm{C}$ for 8 hours, immediately quenching in $65^{\circ} \mathrm{c}$ heated water, artificial ageing by heated in Air oven at $155^{\circ} \mathrm{c}$ for 8 hours.

Hardness is the measure of a materials resistance to plastic deformation against indentation with an applied load [7]. Vickers hardness number (VHN) is a standard way of representing the hardness value of the material. Higher the hardness value greater resistance against the deformation to applied load. ASTM E-384 standard is used has test standard with Vickers hardness testing machine Model HV114. Heat treated specimens were machined to the standardized dimensions as per ASTM E8/E8M to conduct Tensile test. The Tensile test carried out as per ASTM standard on UTM-2T.Tension test specimens were machined to the standardized dimensions as per ASTM E8 as shown in Fig. 1.Tension test specimens were machined to the standardized dimensions as per ASTM E8 as shown in Fig. 1.

\section{RESULTS AND DISCUSSION}

\subsection{Hardness Test}

The result of hardness obtained from the A413 as cast and A413 intermetallic particles alloys at without heat treatment and with T6 solution heat treatment are presented in the following two section. The investigated result are discussed in form of influence of intermetallic particles addition, without heat treatment and T6 solution heat treatment

3.1.1 Effect of intermetallic particles addition on the hardness of $A 413$ \& its alloys

Fig. 1 shows the hardness of A413 and intermetallic particles without heat treatment condition. The hardness of the $\mathrm{A} 413$ with addition of $0.27 \% \mathrm{Al}-5 \% \mathrm{Al}_{3} \mathrm{Ti}$ intermetallic particles is observed slightly increased compare to as cast $\mathrm{A} 413$, further the addition of $0.3 \% \mathrm{Al}-10 \% \mathrm{Al}_{4} \mathrm{Sr}$ intermetallic particles shows on increasing in hardness compare to as cast A413. The addition of $0.55 \%$ intermetallic particles of $\mathrm{Ti}$ and $\mathrm{B}+0.3 \%$ of $\mathrm{Sr}$ particles as Alloy 6A1 shows increase in hardness by about $4 \%$. The modification in the morphology of $\mathrm{Ti}, \mathrm{Bi}$ and $\mathrm{Sr}$ addition in A413 alloy influences the hardness value result in increased as compared to ascast A413 alloy.

The frequently reported depression in eutectic temperature during solidification from the addition of particles appears to parallel the one arising from the addition of mischmetal while it also produces greater eutectic under artificial aging [7], causing the eutectic to shift towards a higher content. This shift increases the proportion $\alpha \mathrm{Al}$ matrix enables more nuclei to form, leading ultimately to a final structure than in the $\mathrm{Al}$ as cast alloy.

Fig. 2 indicates the hardness of A413 and intermetallic particles with T6 solution heat treatment condition. With addition of $0.27 \% \mathrm{Al}-5 \% \mathrm{Al}_{3} \mathrm{Ti}$ intermetallic particles is observed slightly increase in hardness as compare to ascast A413. The addition of $0.55 \%$ intermetallic particles of $\mathrm{Ti}$ and $\mathrm{B}+0.3 \%$ of $\mathrm{Sr}$ particles as Alloy 6A1 shows on increasing in hardness compare to previous value, further by the mixing of $0.55 \% \mathrm{Al}-3 \% \mathrm{TiB}_{2}$ particles to $\mathrm{A} 413$ shows increase in hardness by about $15 \%$. The modification in the morphology of Ti and B addition in A413 alloy influences the hardness value result in increased as compared to ascast A413 alloy.

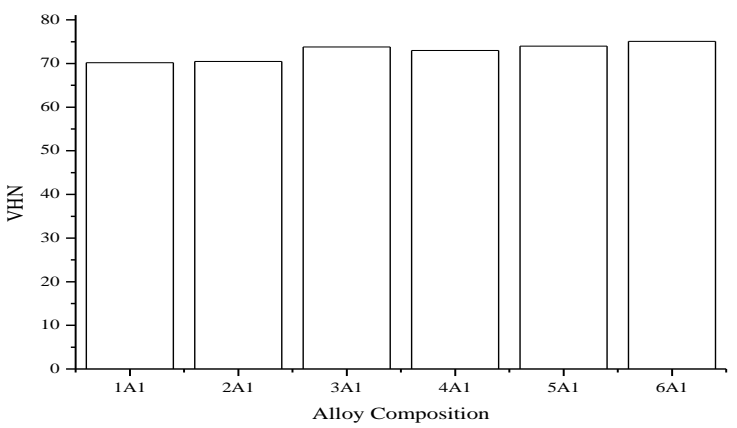

Fig. 1 Influence of intermetallic particles addition on the hardness of $\mathrm{A413} \&$ its alloys without heat treatment

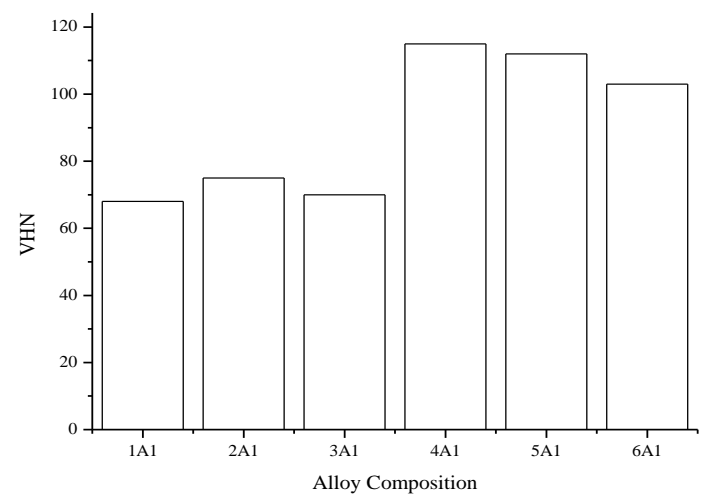

Fig. 2 Influence of intermetallic particles addition on the hardness of A413 \& its alloys with T6 solution heat treatment 


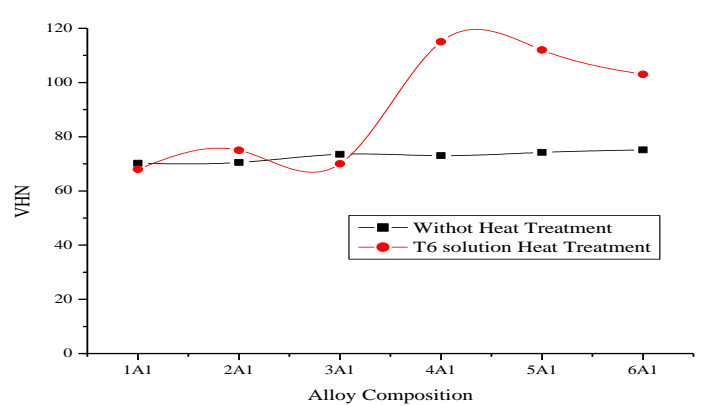

Fig. 3 Influence of intermetallic particles addition on the hardness of A413 \& its alloys without and with T6 solution heat treatment

Fig.3 shows the hardness of 4A1 alloy increases with addition of grain refiners of $\mathrm{TiB}_{2}$ with $\mathrm{T} 6$ solution heat treatment. Then decreases by about $5 \%$ as compared with the alloy 6A1, in which 6A1 is addition of both grain modifier ( $\mathrm{Sr}$ ) and grain refiner ( $\mathrm{Ti} \& \mathrm{~B})$ as shown in fig. 3 . The decrease in the hardness is achieved with the addition of grain modifier with grain refiners. It is observed that the modification of intermetallic particles with T6 solution heat treatment is a dominant factor, resulting in the decrease of the hardness. On the other hand the hardness of A413and addition of intermetallic particles without heat treatment shows slight differences.

3.2 Effect of intermetallic particles addition on the Tensile strength of $A 413$ \& its alloys

Fig. 4(a) shows the Tensile strength of A413 and its alloys without heat treatment condition. The tensile strength of the A413 with addition of $0.27 \% \quad \mathrm{Al}-5 \% \mathrm{Al}_{3} \mathrm{Ti}$ intermetallic particles is observed slightly increased compare to ascast A413, further the addition of $0.55 \%$ intermetallic particles to A413 as in table 1 with alloy 4A1 shows on increasing in tensile strength compare to ascast A413. The addition of $0.55 \% \mathrm{Al}-3 \% \mathrm{TiB}_{2}$ master alloys + $0.3 \% \mathrm{Al}-10 \% \mathrm{Al}_{4} \mathrm{Sr}$ master alloy particles shows increase in tensile strength by about $12 \%$. Fig. 4(b) shows with the addition of grain refiners (Ti. B) and grain modifier (Sr) intermetallic particles the $\%$ elongation increases incrementally. The grain refiners and grain modifier as a significant effect on strength of metals, thus strain hardening mechanism [8-9].

The tensile properties mainly depend on the shape and size of the eutectic silicon morphology in case of eutectic $\mathrm{Al}-\mathrm{Si}$ alloys. The coarse $\mathrm{Si}$ plates of the unmodified plate/rod like silicon structure act as internal stress raiser in the microstructure and provide easy paths for fracture [6]. The addition of $0.275 \% \mathrm{Al}_{3} \mathrm{Ti}, 0.6 \% \mathrm{Al}-3 \% \mathrm{AlB}_{2}, 0.55 \%$ $\mathrm{Al}-3 \% \mathrm{TiB}_{2}$ grain refiners to $\mathrm{A} 413$ alloys converts the predominantly elongated $\alpha$-Al dendritic structure to fine equiaxed $\alpha-\mathrm{Al}$ dendritic structure, thereby enhances the mechanical properties as clearly observed from the Table 4., Similarly, by the addition of grain refiner and with modification the structure becomes finer, large elongated $\alpha$ $\mathrm{Al}$ dendrites gets converted in to fine equiaxed $\alpha-\mathrm{Al}$ dendrites and the elongated eutectic silicon needles become more rounded fine particles [3],. As a result ultimate tensile stress and ductility increases greatly in A413 alloys.

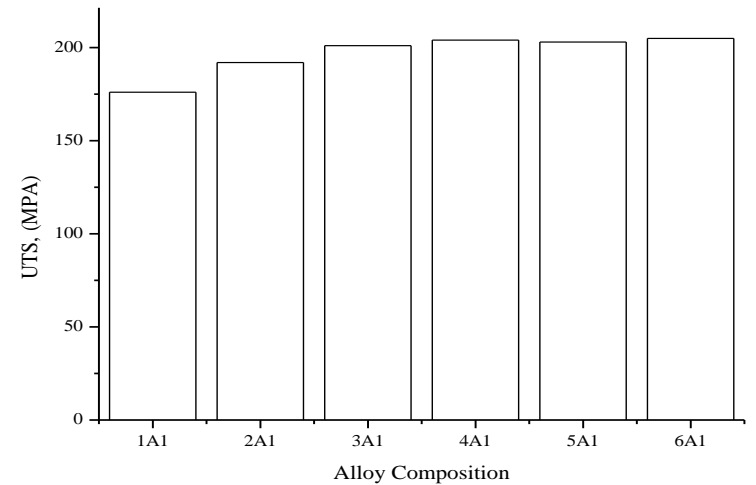

Fig. 4 (a) Influence of intermetallic particles addition on the Tensile strength of A413 \& its alloys without heat treatment

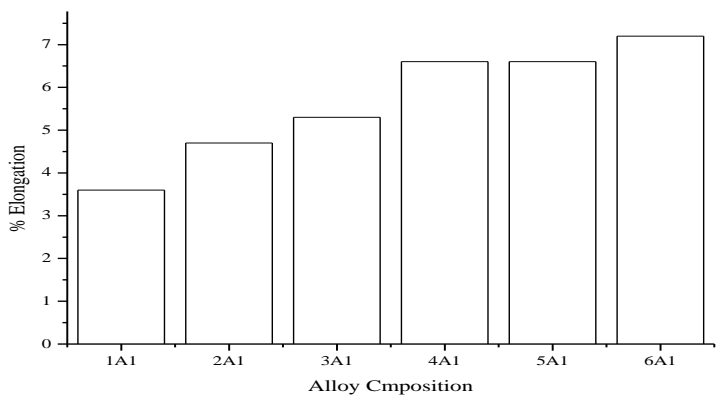

Fig. 4 (b) Influence of intermetallic particles addition on the \% of elongation of $\mathrm{A413} \&$ its alloys without heat treatment

Fig. 5(a) shows the tensile strength of A413 and intermetallic particles with T6 solution heat treatment condition. With addition of $\mathrm{A} 413+0.6 \% \mathrm{Al}-3 \% \mathrm{AlB}_{2}$ intermetallic particles shows increase in tensile strength as compare to ascast A413. The addition of $0.55 \% \mathrm{Al}-3 \% \mathrm{TiB}_{2}$ intermetallic particles shows on slight decreasing in tensile strength compare to previous value; further addition of $0.55 \% \mathrm{Al}-3 \% \mathrm{TiB}_{2}+0.3 \% \mathrm{Al}-10 \% \mathrm{Al}_{4} \mathrm{Sr}$ particles to $\mathrm{A} 413$ shows increase in hardness by about $12 \%$ as compare to ascast. It is observed that from fig. 5(b) \% elongation increases with addition of $\mathrm{Al}-5 \% \mathrm{Al}_{3} \mathrm{Ti}$ intermetallic particles and decrease with $3 \%$ with addition of $\mathrm{Al}-3 \% \mathrm{AlB}_{2}$ $\mathrm{Al}-3 \% \mathrm{TiB}_{2}$ and $\mathrm{Al}-10 \% \mathrm{Al}_{4} \mathrm{Sr}$. Further the $\%$ elongation increase about $2 \%$ with the addition of both grain refiners (Ti \& B) and grain modifier ( $\mathrm{Sr}$ ) intermetallic particles with T6 solution heat treatment.

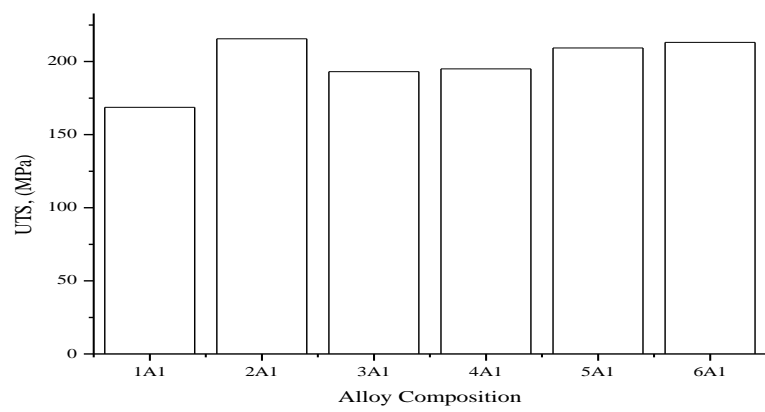

Fig. 5(a) Influence of intermetallic particles addition on the Tensile strength of A413 \& its alloys with T6 solution heat treatment 


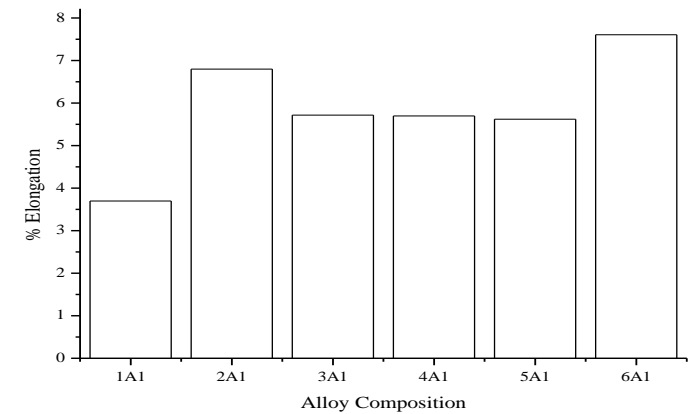

Fig. 5(b) Influence of intermetallic particles addition on the \% of elongation of A413 \& its alloys with T6 solution heat treatment

From fig. 6 it is observed that T6solution heat treatment on A413 alloy increases the ductility as compare to without heat treatment. The presences of silicon particles as eutectic silicon crystals revels higher value of plastic deformation and less ductility. Improvisation in ductility of the A413alloys and influence of intermetallic particles with T6 solution heat treatment leads to the spheroidization of eutectic silicon crystals. Stress required for nucleating a void at a particle-matrix interface would modify the morphology [12].

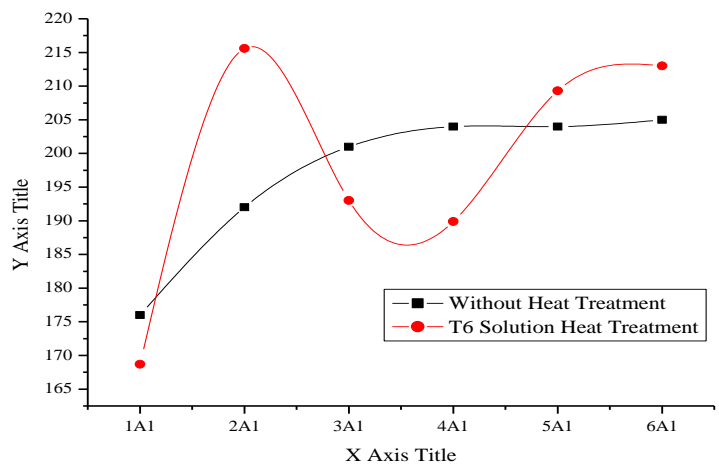

Fig. 6 Influence of intermetallic particles addition on the Tensile Strength of A413 \& its alloys without and with T6 solution heat treatment

\section{CONCLUSIONS}

T6 solution heat treatment on A413 and its alloys shows improvement in hardness and tensile strength. T6 solution heat treatment promotes the distribution of grain refiners $(\mathrm{Ti}, \mathrm{B})$ and grain modifier $(\mathrm{Sr})$, which in turn promotes ductile cracking along the fracture path. Addition of $0.55 \%$ $\left(\mathrm{Al}-3 \% \mathrm{TiB}_{2}\right)$ shows better hardness as compared to other alloys in heat treatment condition. With the adding of both grain refiners ( $\mathrm{Ti} \& \mathrm{~B}$ ) and a grain modifier $(\mathrm{Sr})$ intermetallic particle with T6 solution heat treatment, tensile strength and \% elongation increases. The alloy exhibits fracture where the brittle properties are dominant while heat treatment encourages ductility.

\section{REFERENCES}

1. S. A. Kori, "Studies on the grain refinement and modification of some hypoeutectic and eutectic Al-Si alloys", Ph. D Thesis, IIT Kharagpur, 2000.

2. M. Katsuta, K. Oodoshi and S. Kohara, "Wear resistance of $\mathrm{Al}-\mathrm{Si}$ alloys", Proce. $6^{\text {th }}$ Inter. Conf. on $\mathrm{Al}$ alloys (ICAA-6), Vol.3, July 5-10, 1998, pp 1945-1950.

3. D. G. Mallapur, S. A Kori, and K. RajendraUdpa,
"Influence of $\mathrm{Ti}, \mathrm{B}$ and $\mathrm{Sr} \mathrm{n}$ the microstructural and mechanical properties of A356 alloy", Journal of Materials Science 2010.

4. M. A. MOUSTAFA, F. H. SAMUEL, H. W. DOTY, "Effect of solution heat treatment and additives on the microstructure of Al-Si (A413.1) automotive alloys" of Materials Science 38, 4507-4522, 2003.

5. H R Manohara, Basava T, Sridhara T, "Influence of the Hardness on Treated A413 Alloy", International Journal of Scientific Development and Research (IJSDR) www.ijsdr.org) ISSN: 2455-2631, July 2017 IJSDR, Volume 2, Issue 7, PP 205-209

6. Sridhara T., H R Manohara, Basava T., Dry Wear Behavior of Heat Treated A413 Alloy" Published in Elsevier, Science Direct, Materials Today: Proceedings 4 (2017) 10714-10720, pp 10714-10720

7. 0. El Sebaie, A. M. SAMUEL F. H. SAMUEL, and H. W. DOTY, " The effects of mischmetal, cooling rate and heat treatment on the hardness of A319.1, A356.2 and A413.1 Al-Si casting alloys" Materials Science and Engineering: A, 2008.

8. J.Ye, C. R. Looper J R., D. Y. Lu, C. S. Kang, AFS Trans. 39 (1989) 533-544.

9. ShettyM . N., disloctions and mechanical behaviour of materials, PHI Learning, Pvt.Ltd.,Delhi, India., 2013

10. Yeh, J. W. ;Liu, W. P. the cracking mechanism of silicn particles in 357A al alloys, metallurgical and material transaction A A1996, 27A, 3558-3560

11. Ogris, E. Wahlen, A. Luchinger, H. Uggowitzer, P J. on the silicon spheroidization of in Al-Si alloys, Journal of light metals, 2002, 2(4), 263-269

12. Rajesh Sharma, Anesh Kumar, D k Dwivedi, "Influence of solution temperature on microstructure and mechanical properties of Two cast Al-Si alloys", Materials and Manufacturing Process, 2006 